and for the plants themselves, and a glossary of botanical and horticultural terms used in the volume.

The book is written in a chatty, informal style that will either warm the reader's heart or chill it in equal measure. My reaction was somewhat intermediate. In its approach and style, the volume seems somewhat anachronistic, harkening back to a simpler time, and devoid of any suggestion of a larger picture beyond the guileless love of a plant that is easy to grow and breed. No mention is made of the culinary or medicinal uses of daylilies. The adventive addition of Hemerocallis fulva to the flora of much of the temperate United States is treated as a delightful event, as environmentally an incorrect posture as any.

Alan W. MEerow UNIVERSITY OF FLORIDA 3205 College Avenue FT. LAUderdale, FL 33314

\title{
American Society of Pharmacognosy
}

The 34th annual meeting, July 18-22, 1993 at the Princess Resort on Mission Bay, San Diego, California. For information, call Prof. James B. Gloer, Department of Chemistry, The University of Iowa, (319)335-1361.

\section{ERRATUM}

Omitted from Economic Botany 46:285, column headings for Table 8:

TABLE 8. Presumed genotypes of S. STENOCARPA ACCESSIONS FOR TWELVE PUTATIVE ISOZYME LOCI.

\begin{tabular}{|c|c|c|c|c|c|c|c|c|c|c|c|c|}
\hline Acc. & ACOI & $\mathrm{ACO} 2$ & ADH 1 & GPII & GPI2 & GPI3 & IDHI & IDH2 & PGDI & PGD2 & PGMI & PGM2 \\
\hline
\end{tabular}

